\title{
Pressure-Volume Relationship By Pharmacological Stress Cardiovascular Magnetic Resonance
}

Antonella Meloni ( $\square$ antonella.meloni@ftgm.it )

Fondazione G. Monasterio CNR-Regione Toscana https://orcid.org/0000-0002-2284-8585

Antonio De Luca

University of Trieste: Universita degli Studi di Trieste

Cinzia Nugara

University of Palermo: Universita degli Studi di Palermo

Maria Vaccaro

University of Catania: Universita degli Studi di Catania

Camilla Cavallaro

Campus Bio-Medico University: Universita Campus Bio-Medico di Roma

Chiara Cappelletto

University of Trieste: Universita degli Studi di Trieste

Andrea Barison

Fondazione G. Monasterio CNR-Regione Toscana

Giancarlo Todiere

Fondazione G. Monasterio CNR-Regione Toscana

Chrysanthos Grigoratos

Fondazione G. Monasterio CNR-Regione Toscana

Valeria Calvi

University of Catania: Universita degli Studi di Catania

Giuseppina Novo

University of Palermo: Universita degli Studi di Palermo

Francesco Grigioni

Campus Bio-Medico University: Universita Campus Bio-Medico di Roma

Michele Emdin

Fondazione G. Monasterio CNR-Regione Toscana

Gianfranco Sinagra

University of Trieste: Universita degli Studi di Trieste

Alessia Pepe

Fondazione G. Monasterio CNR-Regione Toscana 
Keywords: cardiovascular magnetic resonance imaging, dipyridamole, end-systolic pressure-volume relation, myocardial contractility

Posted Date: February 5th, 2021

DOI: https://doi.org/10.21203/rs.3.rs-170370/v1

License: (c) (1) This work is licensed under a Creative Commons Attribution 4.0 International License. Read Full License

Version of Record: A version of this preprint was published at The International Journal of Cardiovascular Imaging on November 17th, 2021. See the published version at https://doi.org/10.1007/s10554-02102464-0. 


\section{Abstract}

Background. The variation between rest and peak stress end-systolic pressure-volume relation ( $\triangle \mathrm{ESPVR})$ is an index of myocardial contractility, easily obtained during routine stress echocardiography and never tested during dipyridamole stress-cardiac magnetic resonance (CMR). We assessed the $\triangle E S P V R$ index in patients with known/suspected coronary artery disease (CAD) who underwent dipyridamole stress-CMR.

Methods. One-hundred consecutive patients ( 24 females, $63.76 \pm 10.17$ years) were considered. ESPVR index was evaluated at rest and stress from raw measurement of systolic arterial pressure and endsystolic volume by biplane Simpson's method.

Results. The $\triangle \mathrm{ESPVR}$ index showed a good inter-operator reproducibility.

Mean $\triangle E S P V R$ index was $0.48 \pm 1.45 \mathrm{mmHg} / \mathrm{mL} / \mathrm{m} 2$. $\triangle E S P V R$ index was significantly lower in males than in females.

$\triangle E S P V R$ index was not correlated to rest left ventricular end-diastolic volume index or ejection fraction. Forty-six of 85 patients had myocardial fibrosis detected by the late gadolinium enhancement technique and they showed significantly lower $\triangle E S P V R$ values. An abnormal stress CMR was found in 25 patients and they showed significantly lower $\triangle E S P V R$ values.

During a mean follow-up of $56.34 \pm 30.04$ months, 24 cardiovascular events occurred. At receiveroperating characteristic curve analysis, a $\triangle E S P V R<0.02 \mathrm{mmHg} / \mathrm{mL} / \mathrm{m} 2$ predicted the presence of future cardiac events with a sensitivity of 0.79 and a specificity of 0.68 .

Conclusions. The noninvasive assessment of the $\triangle E S P V R$ index during a dipyridamole stress-CMR exam is feasible and reproducible. The $\triangle E S P V R$ index was independent from rest $L V$ dimensions and function and can be used for a comparative assessment of patients with different diseases. $\triangle E S P V R$ by CMR can be a useful and simple marker for additional prognostic stratification.

\section{Introduction}

Cardiac contractility is the intrinsic capability of heart muscle to generate force and to shorten, ideally independently of changes in heart rate, preload or afterload. Several noninvasive methods have been explored to quantify myocardial contractility and contractile reserve [1]. The end-systolic pressure-volume ratio (ESPVR), defined as the ratio between the systolic pressure and the left ventricular (LV) end-systolic volume indexed for body surface area [2], assessed at rest and during stress, relies on the fact that a positive inotropic stimulation should be accompanied by higher end-systolic pressures with smaller endsystolic volumes. This index has become the most reliable noninvasive measure of contractility, being almost insensitive to changes in preload and afterload [3]. The ESPVR assessment was introduced into the nuclear medicine [2] and the echo laboratories many years ago [4, 5]. Due to the greater availability and lower cost, better spatial and temporal resolutions, and absence of biohazards for the patient and the 
physician [6], echocardiography has become the primary method for determining ESPVR. The $\triangle E S P V R$, calculated as the variation between rest and peak stress ESPVR, was subsequently introduced in the stress-echocardiography as a measure of the heart rate-dependent changes in contractility [4] and it showed significant advantages over the rest or the peak ESPVR value. The $\triangle E S P V R$ is more strongly linked with peak hemodynamic response and stress systolic function [1]. Moreover, it is a more independent measure of true contractile reserve, being unrelated to rest function [1] and to the size of the ventricle [7]. Different $\triangle E S P V R$ cut-offs for the prediction of cardiovascular events were described, depending on the type of stress (exercise, dobutamine or dipyridamole), type of population, and considered end-points $[5,8,3,9-11]$.

In the last decade, stress-cardiac magnetic resonance (CMR) imaging has become a well-established technique for the diagnosis and prognostic stratification of patients with acute and chronic ischemic heart disease [12]. Compared to stress-echocardiography, stress-CMR can provide high-quality images for the visualization of global and regional left ventricular wall motion and highly accurate and reproducible measures of both ventricles [13]. Finally, CMR can provide additional information, such as the detection of perfusion defects and of myocardial fibrosis. Perfusion abnormalities are expected to occur before the regional wall motion abnormalities in the ischemic cascade. Although assessment of myocardial perfusion by stress-echocardiography is technically possible, the methodology is challenging, relatively complicated and lacks of standardization [14]. Several studies demonstrated the additional value of firstpass myocardial perfusion imaging to wall motion assessments during stress-CMR to improve sensitivity for the diagnosis of significant coronary artery disease (CAD) $[15,16]$. Moreover, CMR by late gadolinium enhancement (LGE) is the noninvasive reference standard for replacement fibrosis detection, with significant diagnostic and prognostic implications. Pharmacological stress-CMR can be performed using either inotropic (dobutamine) or vasodilator (adenosine or dipyridamole) stimuli [17] and recent studies have demonstrated the feasibility of exercise stress test, acquiring images immediately following maximal treadmill exercise or with in-scanner cycle ergometers $[18,19]$. Nevertheless, currently vasodilator stress agents remain the mainstay of stress-CMR due to safety issues [20].

The estimation of the $\triangle E S P V R$ by CMR is appealing but only few attempts have been made, based on the invasive measurement of blood pressures [21] and assessment of volumes at rest and during bicycle exercise in healthy endurance athletes in comparison to patients with dilated cardiomyopathy [22]. No data are available in literature evaluating the $\triangle$ ESPVR by dipyridamole stress-CMR.

We assessed the feasibility of a noninvasive estimation of $\triangle E S P V R$ during dipyridamole stress-CMR in patients with known or suspected coronary artery disease (CAD). Moreover, we evaluated the dependence of the $\triangle E S P V R$ on LV size and function, its association with macroscopic myocardial fibrosis, and its prognostic implications.

\section{Materials And Methods}

\section{Study population}


We enrolled 100 consecutive patients ( 24 females, mean age $63.76 \pm 10.17$ years) with known or suspected CAD who underwent dipyridamole stress-CMR in a high volume CMR Laboratory between November 2004 and December 2016, based on the clinical indication [23].

Exclusion criteria were unstable angina, heart failure, known infiltrative or hypertrophic cardiomyopathy, hemodynamic instability, absolute contraindication to CMR and to dipyridamole use, execution of an early revascularization (within 60 days after stress CMR), and a follow-up duration shorter than 6 months.

The electronic medical records of all patients were retrospectively reviewed for demographic data, presence of cardiovascular risk factors and cardiovascular therapy.

Our study complies with the Declaration of Helsinki and was approved by the local ethics committee. All patients gave written informed consent at the time of the CMR.

\section{CMR}

CMR was performed using a 1.5 T MR scanner (GE Excite HD). An eight-element cardiac phased-array receiver surface coil with breath-holding in end-expiration and ECG-gating was used for signal reception.

Patients were asked to refrain from smoking, caffeine, and theophylline for 24 hours, to suspend betablockers for 48 hours, and to maintain fasting for 4 hours. Steady-state free precession (SSFP) cine images were acquired at rest in sequential $8 \mathrm{~mm}$ short axis (no interslice gap) and 2- and 4-chamber views of the left ventricle.

Vasodilatation was induced with dipyridamole injected at $0.84 \mathrm{mg} / \mathrm{kg}$ over 5 minutes. At the end of dipyridamole infusion, $0.1 \mathrm{mmol} / \mathrm{kg}$ of Gadolinium $(0.5 \mathrm{~mol} / \mathrm{l})$ was injected intravenously at $4 \mathrm{~mL} / \mathrm{s}$ followed by saline solution with concomitant acquisition of three short-axis views of the left ventricle with first-pass perfusion technique using saturation-prepared T1-weighted fast gradient-echo sequence. Steady-state free precession cine images were then acquired at stress in 4- and 2-chamber views and in basal, medium and apical short-axis views (3 slices per heart beat) with the same geometry used at rest, according to the standard stress-CMR protocols [24]. Aminophylline was intravenously injected to null the effect of dipyridamole at the end of the stress test. About after ten minutes when cardiac frequency and blood pressure returned to the basal state, $0.1 \mathrm{mmol} / \mathrm{kg}$ of Gadolinium was injected intravenously at 4 $\mathrm{mL} / \mathrm{s}$ followed by saline solution with concomitant acquisition of three short-axis views of the left ventricle with first-pass perfusion technique using saturation-prepared T1-weighted fast gradient-echo sequence. Eight minutes after contrast injection, breath-hold contrast-enhanced segmented T1-weighted inversion-recovery gradient-echo sequence was acquired with the same prescriptions for cine images to detect LGE. The inversion time was individually adjusted to null normal myocardium.

\section{Image analysis}

CMR images were blindly analyzed using certified software (cvi ${ }^{42}$, Circle CVI, Calgary, Alberta, Canada). 
LV end-diastolic and end-systolic volumes (EDV, ESV) were obtained at rest and at peak of stress from apical vertical long-axis view and horizontal long-axis view using the biplane Simpson's method (Figure 1). The LV ejection fraction (EF) was calculated according to the formula EF = (EDV - ESV)/EDV $100 \%$. EDV and ESV were normalized for the body surface area (EDVI and ESVI).

LV EDV and ESV were calculated at rest also by cine short-axis slices using the standard method [25].

The 17-segment model of the American Heart Association/American College of Cardiology was applied [26] for the analysis of wall motion, perfusion and myocardial fibrosis.

Wall motion at rest and after dipyridamole was analyzed by classifying each myocardial segment as normal, hypokinetic, akinetic or diskinetic. Ischemia was defined as stress-induced new and/or worsening of pre-existing wall motion abnormality. Perfusion defect was evaluated at rest and after stress and was defined as persistent delay of enhancement during first pass of the contrast agent for $>3$ heart beats at maximum signal intensity in the cavity of the left ventricle.

The LGE was evaluated visually using a two-point scale (enhancement absent or present). Enhancement was considered present whenever it was visualized in two different views. The number of myocardial segments showing LGE was assessed.

\section{Pressure assessment}

Systolic blood pressures at rest and stress were recorded in the right arm by using a MRI-compatible sphygmomanometer immediately before the acquisition of cine images. The end-systolic pressure was obtained as LV end-systolic pressure $=0.9 *$ systolic blood pressure.

\section{End-systolic pressure-volume assessment}

The ESPVR index $(\mathrm{mmHg} / \mathrm{mL} / \mathrm{m} 2)$ was obtained as the ratio of the end-systolic pressure to the LVESVI calculated from the long axis views. The ESPVR index was determined at rest and at peak stress. The $\triangle E S P V R$ index was calculated as the difference between rest and peak stress ESPVR [5].

\section{Follow-up}

Patients follow-up was performed by phone interview or review of informatic medical records by researchers unaware of the patients' CMR results.

The following end-points were considered: non-fatal myocardial infarction, revascularization defined as elective procedure 60 days after CMR, hospitalisation for unstable angina or heart failure, ventricular arrhythmias, and cardiac death.

In cases of multiple events in a given patient, the first event was considered.

\section{Statistical analysis}


All data were analyzed using SPSS version 17.0 (SPSS Inc., Chicago, IL, USA) and MedCalc for Windows version 7.2.1.0 (MedCalc Software, Mariakerke, Belgium) statistical packages.

Continuous variables were described as mean \pm standard deviation (SD). Categorical variables were expressed as frequencies and percentages.

The Kolomogorov-Smirnov test showed a non-normal distribution for rest and stress ESPVR and $\triangle \mathrm{ESPVR}$ values. Comparisons between groups were made by the Wilcoxon rank sum test and correlation analysis was performed using the Spearman's test .

A receiver-operating characteristic $(\mathrm{ROC})$ analysis was used to obtain the best prognostic predictor for $\triangle$ ESPVR.

A 2-tailed $P<0.05$ was considered statistically significant.

\section{Reproducibility analysis}

To evaluate the inter-observer variability, images from 20 patients were presented in random order to another operator. A paired Wilcoxon signed rank test was applied to detect significant differences between the two datasets and the intraclass correlation coefficient (ICC) was obtained from a two-way random effects model with measures of absolute agreement. An ICC $\geq 0.75$ was considered excellent. The agreement between measurements was evaluated through the use of Bland-Altman (BA) analysis by calculating the bias (mean difference) and the $95 \%$ limits of agreement (mean \pm 1.96 SDs).

\section{Results}

\section{Patients characteristics}

By selection, technically adequate images were obtained in all patients at rest and during stress, and no test was interrupted because of major complications.

Table 1 shows the main clinical and CMR findings of the study population. Mean ESPVR index at rest and peak stress was, respectively, $4.84 \pm 2.47 \mathrm{mmHg} / \mathrm{mL} / \mathrm{m} 2$ and $5.33 \pm 3.16 \mathrm{mmHg} / \mathrm{mL} / \mathrm{m} 2$ and mean $\triangle$ ESPVR index was $0.48 \pm 1.45 \mathrm{mmHg} / \mathrm{mL} / \mathrm{m} 2$.

\section{Inter-operator reproducibility}

In 20 randomly selected patients no significant difference was detected between the $\triangle E S P V R$ values calculated by the two operators $(0.62 \pm 1.63 \mathrm{mmHg} / \mathrm{mL} / \mathrm{m} 2$ vs $0.75 \pm 1.62 \mathrm{mmHg} / \mathrm{mL} / \mathrm{m} 2 ; \mathrm{P}=0.478)$. The ICC was excellent $(0.959 ; 95 \% \mathrm{Cl}=0.899-0.984)$. The BA analysis showed a bias of -0.11 while BA limits were -1.34 and 1.11.

\section{Correlates of $\triangle \mathrm{ESPVR}$}


Rest LV volumes calculated using the biplane Simpson's method were comparable to volumes obtained from short axis images using standard method (EDVl: mean difference $1.78 \pm 17.89 \mathrm{ml} / \mathrm{m} 2 \mathrm{P}=0.588$ and ESVI: mean difference $-1.80 \pm 8.49 \mathrm{ml} / \mathrm{m} 2 \mathrm{P}=0.344$ ).

$\triangle E S P V R$ index was not associated to age $(R=-0.107 ; P=0.290)$ but it was significantly lower in males than in females $(0.25 \pm 1.24 \mathrm{mmHg} / \mathrm{mL} / \mathrm{m} 2$ vs $1.22 \pm 1.79 \mathrm{mmHg} / \mathrm{mL} / \mathrm{m} 2 ; P=0.017)$.

Patients without and with diabetes showed comparable values of $\triangle E S P V R(0.56 \pm 1.58 \mathrm{mmHg} / \mathrm{mL} / \mathrm{m} 2 \mathrm{vs}$ $0.26 \pm 0.99 \mathrm{mmHg} / \mathrm{mL} / \mathrm{m} 2 ; \mathrm{P}=0.497)$.

A significant inverse relationship between ESPVR index and LVEDVI was present at rest $(R=-0.795$; $P<0.0001)$ and peak stress $(R=-0.779 ; P<0.0001) . \triangle E S P V R$ index was not correlated to rest LVEDVI $(R=-0.120 ; P=0.233)$ while it showed a weak correlation with stress LVEDVI $(R=-0.240 ; P=0.016)$.

A significant positive relationship between ESPVR index and LVEF was present at rest $(R=0.841$; $P<0.0001)$ and stress $(R=0.882 ; P<0.0001) . \triangle E S P V R$ index was not correlated to rest LVEF $(R=0.193$; $P=0.055)$ but it was significantly correlated with stress LVEF $(R=0.557 ; P<0.0001)$.

LGE sequences were acquired in 85 patients. Forty-six (54.1\%) patients showed myocardial fibrosis: 27 with an ischemic pattern (11 transmural, 10 subendocardial, and 6 transmural and subendocardial), 15 with a non-ischemic pattern ( 11 mid-wall, 3 epicardial, and 1 both mid-wall and epicardial), and 4 with a mixed pattern. Patients with myocardial fibrosis showed a significantly lower $\triangle E S P V R$ index compared to patients without myocardial fibrosis $(0.19 \pm 1.08 \mathrm{mmHg} / \mathrm{mL} / \mathrm{m} 2$ vs $0.82 \pm 1.73 \mathrm{mmHg} / \mathrm{mL} / \mathrm{m} 2 ; P=0.031)$ (Figure 2A). Mean number of segments with myocardial fibrosis was $3.96 \pm 2.43$ and a significant correlation was detected between the $\triangle E S P V R$ index and the number of segments with myocardial fibrosis $(R=-0.519 ; P<0.0001)$.

An abnormal stress-CMR was found in $25(25.0 \%)$ patients; 19 patients had a reversible stress perfusion defect in at least one myocardial segment and 6 a reversible stress perfusion defect plus worsening of stress wall motion in comparison with rest. $\triangle E S P V R$ index was significantly lower in patients with abnormal stress-CMR than in patients with normal stress-CMR $(0.21 \pm 1.57 \mathrm{mmHg} / \mathrm{mL} / \mathrm{m} 2$ vs $0.57 \pm 1.40$ $\mathrm{mmHg} / \mathrm{mL} / \mathrm{m} 2 ; \mathrm{P}=0.035$ ) (Figure 2B).

\section{Follow-up data and ROC analysis}

Mean follow-up time was $56.34 \pm 30.04$ months (median=52.88 months).

Cardiac events were recorded in 24 (24\%) patients: 3 cardiac deaths, 11 revascularizations after unstable angina $(\mathrm{N}=10)$ or myocardial infarction $(\mathrm{N}=1), 1$ ventricular arrhythmia, and 9 hospitalisations for heart failure $(\mathrm{N}=2)$ or unstable angina $(\mathrm{N}=7)$.

Mean time from the CMR scan to the development of a cardiac event was $36.19 \pm 28.21$ months (range 3125 months). Mean age at the appearance of the cardiac events was $68.25 \pm 10.21$ years (range 49-85 
years).

Patients with events showed a significant lower $\triangle E S P V R$ index $(-0.14 \pm 0.91 \mathrm{mmHg} / \mathrm{mL} / \mathrm{m} 2$ vs $0.68 \pm 1.53$ $\mathrm{mmHg} / \mathrm{mL} / \mathrm{m} 2 ; \mathrm{P}=0.002$ ) (Figure 3A).

At ROC curve analysis, $\triangle E S P V R$ index $<0.02 \mathrm{mmHg} / \mathrm{mL} / \mathrm{m} 2$ predicted the presence of future cardiac events with a sensitivity of 0.79 and a specificity of $0.68(P=0.0004)$. The area under the curve was 0.71 (95\% Confidence interval: 0.61-0.79) (Figure 3B).

If only the 75 patients with a normal stress CMR exam were considered, $\triangle E S P V R$ index $<0.02 \mathrm{~mm}$ $\mathrm{Hg} / \mathrm{mL} / \mathrm{m} 2$ remained the best value to predict future events, with a sensitivity of 0.69 and a specificity of 0.73 .

\section{Discussion}

We showed for the first time that a noninvasive and reproducible estimation of $\triangle E S P V R$ can be easily done during dipyridamole stress-CMR. Mean $\triangle E S P V R$ index in our population of patients with known or suspected CAD was $0.48 \pm 1.45 \mathrm{mmHg} / \mathrm{mL} / \mathrm{m} 2$. Although it is hazardous to compare different techniques and study populations, by dipyridamole stress-echocardiography Bombardini et al found a mean value of $2.75 \pm 2.17 \mathrm{mmHg} / \mathrm{mL} / \mathrm{m} 2$ in 33 subjects with a low pretest probability of coronary artery disease and of $-0.10 \pm 2.39 \mathrm{mmHg} / \mathrm{mL} / \mathrm{m} 2$ in 140 patients with $\mathrm{CAD}$, diagnosed in presence of history of myocardial infarction or coronary revascularization and/or the presence of $\geq 1$ angiographically documented coronary stenosis $>50 \%[7]$.

We found out that $\triangle E S P V R$ index was associated to gender, being significantly higher in females. To our knowledge no previous study has attempted to explore the gender differences in the $\triangle E S P V R$ values. Jellis et al found a comparable percentage of males and females with a reduced $\triangle E S P V R$ index after exercise [1], but no data are available in literature about direct comparisons of the mean values for $\triangle E S P V R$ index by gender. Although it is insidious to translate results from experimental studies, our data find echo in the work of Capasso et al, aimed at defining the contractile properties of left ventricular papillary muscles in the rat [27]. The authors found out that, although there was no difference in peak isometric tension developed, the males took longer to develop maximal force and relaxed more slowly. In addition, an increase in external calcium did not affect these gender-specific contractile properties.

Rest and peak stress end-systolic pressure-volume ratios were dependent on chamber size, resulting lower in larger ventricles. Conversely, the rest LVEDVI did not affect the $\triangle E S P V R$ index. These findings are in agreement with a recent study based on stress echocardiography [7] and emphasize that the $\triangle E S P V R$ index represents an optimal index for comparative assessments even in patients with pathological left ventricular dilatation, without the need of size normalization. Moreover, we detected a significant positive correlation between $\triangle E S P V R$ index and stress systolic function, that is a central clinical determinant of LV contractility and contractile reserve [1]. 
A reduced $\triangle E S P V R$ index was associated with the presence of macroscopic myocardial fibrosis, detected by the LGE technique. Myocardial fibrosis is a complex process resulting in the excessive accumulation of the extracellular matrix proteins by cardiac fibroblasts converted to their activated form, often known as myofibroblasts [28]. Fibrotic extracellular matrix increases the stiffness and decreases the compliance of the tissue, negatively affecting both contraction and relaxation of the heart and leading to a progressive decrease in contractility [29-31]. In the subgroup of LGE-positive patients, a negative correlation was detected between the $\triangle E S P V R$ index and the number of segments with myocardial fibrosis, suggesting that the contractility worsens as the extent of macroscopic myocardial fibrosis increases.

Patients with an abnormal stress CMR showed a significant lower $\triangle E S P V R$ index than patients with a normal stress CMR. However, there was an overlap between the two groups. This finding suggests that a depressed $\triangle E S P V R$ index can be a marker of initial and latent LV dysfunction in patients with minor forms of anatomically significant CAD which are unable to give absolute subendocardial under perfusion necessary to induce true regional ischemia. In fact, it has been shown that in patients with negative stress-echocardiography by standard wall motion criteria, a $\triangle E S P V R$ index $<1.5 \mathrm{mmHg} / \mathrm{ml} / \mathrm{m} 2$, as determined by ROC analysis cut-off, was an independent predictor of total events [3].

A lower $\triangle E S P V R$ index was associated with the development of cardiovascular events. With a ROC analysis, a $\triangle E S P V R$ index $<0.02 \mathrm{mmHg} / \mathrm{mL} / \mathrm{m} 2$ predicted future events with good sensitivity and specificity. Further dipyridamole stress-CMR studies are needed to confirm this observation in order to include definitively this parameter in the clinical practice.

\section{Limitations}

1) The study population was not so large because in our Laboratory we used also other stress-agents, such as dobutamine and adenosisne. Moreover, we were used to scan patients in all field of cardiology, not only patients with sudspicion of ischemic disease.

2) As only non-invasive measurements of blood pressure were available, the systolic cuff pressure was used as a surrogate for end-systolic pressure, introducing an approximation.

3) We assumed that V0 (zero-volume intercept of the end-systolic pressure-volume relationship) was negligible. The calculation of $\mathrm{V} 0$ requires the use of invasively derived pressure-volume loops, which was not possible in this noninvasive study. However, previous studies reported that V0 remains unaltered during exercise or changes in loading conditions [32], making the LVESPVR index a valid approximation of end-systolic elastance [33].

4) Short axis slices are used in non-stress-CMR for the assessment of LV volumes and function and represent the gold standard [25]. However, in the stress-CMR, the evaluation of function parameters during stress can be performed using the long axis views, in order to reduce the total scan time for safety reasons [24]. Anyway, both approaches were significantly correlated in our study population and it has 
been shown that, when compared to an ex vivo standard, both, short axis and long axis techniques are highly accurate for the quantification of left ventricular volumes and mass [34].

5) The obtained cut-off can be applied only for $\triangle E S P V R$ indexes obtained during a dipyridamole stressCMR exam, since it is entirely likely that prognostically meaningful cut-offs for this index are stressspecific [35].

\section{Conclusions}

The noninvasive assessment of the $\triangle E S P V R$ index during a dipyridamole stress-CMR exam is feasible, reproducible, free and it does not affect the imaging time. $\triangle E S P V R$ index was independent from rest chamber size, while it was reduced in presence of abnormal stress-CMR and myocardial fibrosis. In patients with known or suspected CAD who undergo dipyridamole stress-CMR $\triangle E S P V R$ index can provide a prognostic stratification for relevant cardiac events with an optimal cut-off of $0.02 \mathrm{mmHg} / \mathrm{mL} / \mathrm{m} 2$.

\section{Declarations}

\section{Funding}

No funding was received.

\section{Competing interests}

The authors declare that they have no competing interests.

\section{Availability of data and material}

The datasets analysed during the current study are available from the corresponding author on reasonable request.

\section{Code availability}

Not applicable.

\section{Ethics approval}

Our study complies with the Declaration of Helsinki and was approved by the local ethics committee.

\section{Consent to participate}

All patients gave written informed consent at the time of the CMR.

\section{Consent for publication}

Not applicable. 


\section{ACKNOWLEDGEMENTS}

We thank Claudia Santarlasci for skillful secretarial work and all patients for their cooperation.

\section{References}

1. Jellis CL, Jenkins C, Leano R, Martin JH, Marwick TH (2010) Reduced end-systolic pressure-volume ratio response to exercise: a marker of subclinical myocardial disease in type 2 diabetes. Circ Cardiovasc Imaging 3 (4):443-449

2. Slutsky R, Karliner J, Gerber K, Battler A, Froelicher V, Gregoratos G, Peterson K, Ashburn W (1980) Peak systolic blood pressure/end-systolic volume ratio: assessment at rest and during exercise in normal subjects and patients with coronary heart disease. Am J Cardiol 46 (5):813-820

3. Bombardini T, Galderisi M, Agricola E, Coppola V, Mottola G, Picano E (2008) Negative stress echo: further prognostic stratification with assessment of pressure-volume relation. Int J Cardiol 126 (2):258-267

4. Bombardini T, Correia MJ, Cicerone C, Agricola E, Ripoli A, Picano E (2003) Force-frequency relationship in the echocardiography laboratory: a noninvasive assessment of Bowditch treppe? $\mathrm{J}$ Am Soc Echocardiogr 16 (6):646-655

5. Grosu A, Bombardini T, Senni M, Duino V, Gori M, Picano E (2005) End-systolic pressure/volume relationship during dobutamine stress echo: a prognostically useful non-invasive index of left ventricular contractility. Eur Heart J 26 (22):2404-2412

6. Sicari R, Cortigiani L (2017) The clinical use of stress echocardiography in ischemic heart disease. Cardiovascular Ultrasound 15 (1):7. doi:10.1186/s12947-017-0099-2

7. Bombardini T, Mulieri LA, Salvadori S, Costantino MF, Scali MC, Marzilli M, Picano E (2017) Pressurevolume Relationship in the Stress-echocardiography Laboratory: Does (Left Ventricular End-diastolic) Size Matter? Rev Esp Cardiol (Engl Ed) 70 (2):96-104

8. Bombardini T, Agrusta M, Natsvlishvili N, Solimene F, Pap R, Coltorti F, Varga A, Mottola G, Picano E (2005) Noninvasive assessment of left ventricular contractility by pacemaker stress echocardiography. Eur J Heart Fail 7 (2):173-181

9. Agricola E, Meris A, Oppizzi M, Bombardini T, Pisani M, Fragasso G, Margonato A (2008) Rest and stress echocardiographic predictors of prognosis in patients with left ventricular dysfunction and functional mitral regurgitation. Int J Cardiol 124 (2):247-249

10. Otasevic P, Popovic ZB, Vasiljevic JD, Vidakovic R, Pratali L, Vlahovic A, Neskovic AN (2005) Relation of myocardial histomorphometric features and left ventricular contractile reserve assessed by highdose dobutamine stress echocardiography in patients with idiopathic dilated cardiomyopathy. Eur $\mathrm{J}$ Heart Fail 7 (1):49-56

11. Bombardini T, Costantino MF, Sicari R, Ciampi Q, Pratali L, Picano E (2013) End-systolic elastance and ventricular-arterial coupling reserve predict cardiac events in patients with negative stress echocardiography. Biomed Res Int 2013:235194 
12. Foley JR, Plein S, Greenwood JP (2017) Assessment of stable coronary artery disease by cardiovascular magnetic resonance imaging: Current and emerging techniques. World $\mathrm{J}$ Cardiol 9 (2):92-108

13. Karamitsos TD, Hudsmith LE, Selvanayagam JB, Neubauer S, Francis JM (2007) Operator induced variability in left ventricular measurements with cardiovascular magnetic resonance is improved after training. J Cardiovasc Magn Reson 9 (5):777-783

14. Sharma R, Pellerin D (2009) Stress echocardiogaphy: a useful test for assessing cardiac risk in diabetes. Vasc Health Risk Manag 5 (1):1-7

15. Gebker R, Jahnke C, Manka R, Hamdan A, Schnackenburg B, Fleck E, Paetsch I (2008) Additional value of myocardial perfusion imaging during dobutamine stress magnetic resonance for the assessment of coronary artery disease. Circ Cardiovasc Imaging 1 (2):122-130

16. Lubbers DD, Janssen CH, Kuijpers D, van Dijkman PR, Overbosch J, Willems TP, Oudkerk M (2008) The additional value of first pass myocardial perfusion imaging during peak dose of dobutamine stress cardiac MRI for the detection of myocardial ischemia. Int J Cardiovasc Imaging 24 (1):69-76

17. Chotenimitkhun R, Hundley WG (2011) Pharmacological stress cardiovascular magnetic resonance. Postgrad Med 123 (3):162-170

18. Jekic M, Foster EL, Ballinger MR, Raman SV, Simonetti OP (2008) Cardiac function and myocardial perfusion immediately following maximal treadmill exercise inside the MRI room. J Cardiovasc Magn Reson 10:3

19. Habert P, Bentatou Z, Aldebert P, Finas M, Bartoli A, Bal L, Lalande A, Rapacchi S, Guye M, Kober F, Bernard M, Jacquier A (2018) Exercise stress CMR reveals reduced aortic distensibility and impaired right-ventricular adaptation to exercise in patients with repaired tetralogy of Fallot. PLoS One 13 (12):e0208749

20. Le TT, Huang W, Bryant JA, Cook SA, Chin CW (2017) Stress cardiovascular magnetic resonance imaging: current and future perspectives. Expert Rev Cardiovasc Ther 15 (3):181-189

21. Pingitore A, Aquaro GD, Lorenzoni V, Gallotta M, De Marchi D, Molinaro S, Cospite V, Passino C, Emdin M, Lombardi M, Lionetti V, L'Abbate A (2013) Influence of preload and afterload on stroke volume response to low-dose dobutamine stress in patients with non-ischemic heart failure: a cardiac MR study. Int J Cardiol 166 (2):475-481

22. Claessen G, Schnell F, Bogaert J, Claeys M, Pattyn N, De Buck F, Dymarkowski S, Claus P, Carre F, Van Cleemput J, La Gerche A, Heidbuchel H (2018) Exercise cardiac magnetic resonance to differentiate athlete's heart from structural heart disease. Eur Heart J Cardiovasc Imaging 19 (9):1062-1070

23. Montalescot G, Sechtem U, Achenbach S, Andreotti F, Arden C, Budaj A, Bugiardini R, Crea F, Cuisset T, Di Mario C, Ferreira JR, Gersh BJ, Gitt AK, Hulot JS, Marx N, Opie LH, Pfisterer M, Prescott E, Ruschitzka F, Sabate M, Senior R, Taggart DP, van der Wall EE, Vrints CJ, Zamorano JL, Achenbach S, Baumgartner H, Bax JJ, Bueno H, Dean V, Deaton C, Erol C, Fagard R, Ferrari R, Hasdai D, Hoes AW, Kirchhof P, Knuuti J, Kolh P, Lancellotti P, Linhart A, Nihoyannopoulos P, Piepoli MF, Ponikowski P, Sirnes PA, Tamargo JL, Tendera M, Torbicki A, Wijns W, Windecker S, Knuuti J, Valgimigli M, Bueno H, 
Claeys MJ, Donner-Banzhoff N, Erol C, Frank H, Funck-Brentano C, Gaemperli O, Gonzalez-Juanatey JR, Hamilos M, Hasdai D, Husted S, James SK, Kervinen K, Kolh P, Kristensen SD, Lancellotti P, Maggioni AP, Piepoli MF, Pries AR, Romeo F, Ryden L, Simoons ML, Sirnes PA, Steg PG, Timmis A, Wijns W, Windecker S, Yildirir A, Zamorano JL (2013) 2013 ESC guidelines on the management of stable coronary artery disease: the Task Force on the management of stable coronary artery disease of the European Society of Cardiology. Eur Heart J 34 (38):2949-3003

24. Kramer CM, Barkhausen J, Bucciarelli-Ducci C, Flamm SD, Kim RJ, Nagel E (2020) Standardized cardiovascular magnetic resonance imaging (CMR) protocols: 2020 update. J Cardiovasc Magn Reson $22(1): 17$

25. Pontone G, Andreini D, Bertella E, Loguercio M, Guglielmo M, Baggiano A, Aquaro GD, Mushtaq S, Salerni S, Gripari P, Rossi C, Segurini C, Conte E, Beltrama V, Giovannardi M, Veglia F, Guaricci Al, Bartorelli AL, Agostoni P, Pepi M, Masci PG (2016) Prognostic value of dipyridamole stress cardiac magnetic resonance in patients with known or suspected coronary artery disease: a mid-term followup study. Eur Radiol 26 (7):2155-2165

26. Cerqueira MD, Weissman NJ, Dilsizian V, Jacobs AK, Kaul S, Laskey WK, Pennell DJ, Rumberger JA, Ryan T, Verani MS (2002) Standardized myocardial segmentation and nomenclature for tomographic imaging of the heart. A statement for healthcare professionals from the Cardiac Imaging Committee of the Council on Clinical Cardiology of the American Heart Association. Circulation 105 (4):539-542

27. Capasso JM, Remily RM, Smith RH, Sonnenblick EH (1983) Sex differences in myocardial contractility in the rat. Basic Res Cardiol 78 (2):156-171

28. Travers JG, Kamal FA, Robbins J, Yutzey KE, Blaxall BC (2016) Cardiac Fibrosis: The Fibroblast Awakens. Circ Res 118 (6):1021-1040

29. Kong P, Christia P, Frangogiannis NG (2014) The pathogenesis of cardiac fibrosis. Cell Mol Life Sci $71(4): 549-574$

30. Yarbrough WM, Mukherjee R, Stroud RE, Rivers WT, Oelsen JM, Dixon JA, Eckhouse SR, Ikonomidis JS, Zile MR, Spinale FG (2012) Progressive induction of left ventricular pressure overload in a large animal model elicits myocardial remodeling and a unique matrix signature. J Thorac Cardiovasc Surg $143(1): 215-223$

31. van den Borne SW, Diez J, Blankesteijn WM, Verjans J, Hofstra L, Narula J (2010) Myocardial remodeling after infarction: the role of myofibroblasts. Nat Rev Cardiol 7 (1):30-37

32. Little WC, Cheng CP, Peterson T, Vinten-Johansen J (1988) Response of the left ventricular endsystolic pressure-volume relation in conscious dogs to a wide range of contractile states. Circulation 78 (3):736-745

33. Sagawa K, Suga H, Shoukas AA, Bakalar KM (1977) End-systolic pressure/volume ratio: a new index of ventricular contractility. Am J Cardiol 40 (5):748-753

34. Childs H, Ma L, Ma M, Clarke J, Cocker M, Green J, Strohm O, Friedrich MG (2011) Comparison of long and short axis quantification of left ventricular volume parameters by cardiovascular magnetic 
resonance, with ex-vivo validation. J Cardiovasc Magn Reson 13:40

35. Bombardini T, Zoppe M, Ciampi Q, Cortigiani L, Agricola E, Salvadori S, Loni T, Pratali L, Picano E (2013) Myocardial contractility in the stress echo lab: from pathophysiological toy to clinical tool. Cardiovasc Ultrasound 11:41

\section{Tables}

Table 1. Demographic, clinical and CMR findings of the study population. 


\begin{tabular}{|c|c|}
\hline \multicolumn{2}{|l|}{ Demographics } \\
\hline Age (years) & $63.76 \pm 10.17$ \\
\hline Females, $N(\%)$ & $24(24.0)$ \\
\hline \multicolumn{2}{|l|}{ Heart rate (bpm) } \\
\hline rest & $65.70 \pm 13.09$ \\
\hline stress & $87.69 \pm 14.78$ \\
\hline \multicolumn{2}{|c|}{ End-systolic pressure ( $\mathrm{mmHg})$} \\
\hline rest & $129.42 \pm 17.55$ \\
\hline stress & $122.98 \pm 17.97$ \\
\hline \multicolumn{2}{|l|}{ Cardiovascular risk factors } \\
\hline Diabetes, $N(\%)$ & $27(27.0)$ \\
\hline Hypertension, N(\%) & $60(60.0)$ \\
\hline Dyslipidemia, $N(\%)$ & $56(56.0)$ \\
\hline Smoking, $N(\%)$ & $24(24.0)$ \\
\hline Family history, $\mathrm{N}(\%)$ & $49(49.0)$ \\
\hline At least one CVRF, N(\%) & $92(92.0)$ \\
\hline \multicolumn{2}{|l|}{ Medical therapy } \\
\hline Diuretics, $N(\%)$ & $17(17)$ \\
\hline ACE-inhibitors, $N(\%)$ & $27(27)$ \\
\hline Sartans, $N(\%)$ & $18(18)$ \\
\hline Aspirin, N(\%) & $62(62)$ \\
\hline Beta-blockers, N(\%) & $44(44)$ \\
\hline \multicolumn{2}{|l|}{ CMR data } \\
\hline \multicolumn{2}{|l|}{ LVEDVI (ml/m2) } \\
\hline rest & $80.33 \pm 20.22$ \\
\hline stress & $86.18 \pm 19.47$ \\
\hline \multicolumn{2}{|l|}{ LVESVI (ml/m2) } \\
\hline rest & $33.19 \pm 16.89$ \\
\hline stress & $30.33 \pm 16.96$ \\
\hline
\end{tabular}




\begin{tabular}{|ll|}
\hline LVEF (\%) & \\
rest & $60.25 \pm 11.16$ \\
stress & $66.36 \pm 11.85$ \\
\hline ESPVR index (mmHg/mL/m2) & \\
rest & $4.84 \pm 2.47$ \\
stress & $5.33 \pm 3.16$ \\
\hline DESPVR index (mmHg/mL/m2) & $0.48 \pm 1.45$ \\
\hline Myocardial fibrosis, $\mathbf{N}(\%)$ & $46 / 85(54.1)$ \\
\hline Stress CMR, N(\%) & \\
normal & $75(75.0)$ \\
perfusion defect & $19(19.0)$ \\
perfusion+motion defect & $6(6.0)$ \\
\hline
\end{tabular}

$\mathrm{N}=$ number; $\mathrm{CVRF}=$ cardiovascular risk factor; $\mathrm{LV}=$ left ventricular; $\mathrm{EDVI}=$ end-diastolic volume index; $E S V I=e n d-s y s t o l i c$ volume index; $E F=e j e c t i o n$ fraction; $E S P V R$ end-systolic pressure-volume ratio; $\triangle \mathrm{ESPVR}=$ delta end-systolic pressure-volume ratio; $\mathrm{CMR}=$ cardiac magnetic resonance.

\section{Figures}

\section{Basal CMR}
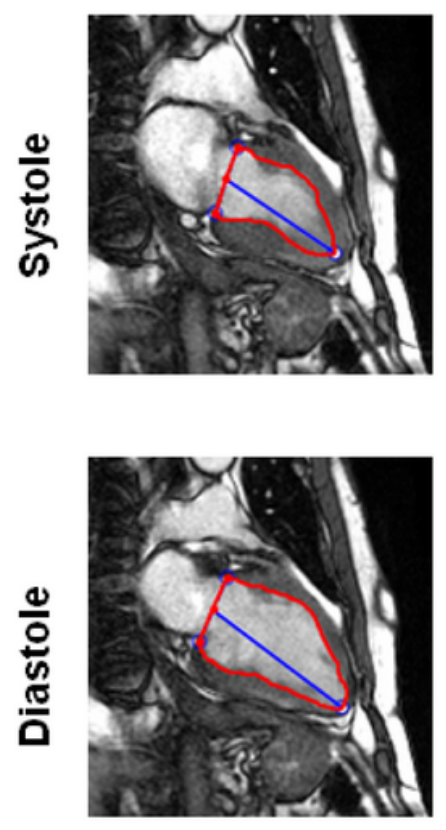

2 chamber-view
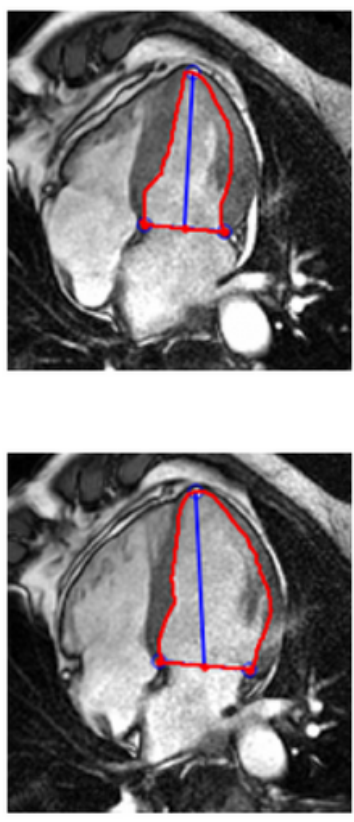

4 chamber-view

\section{Stress CMR}
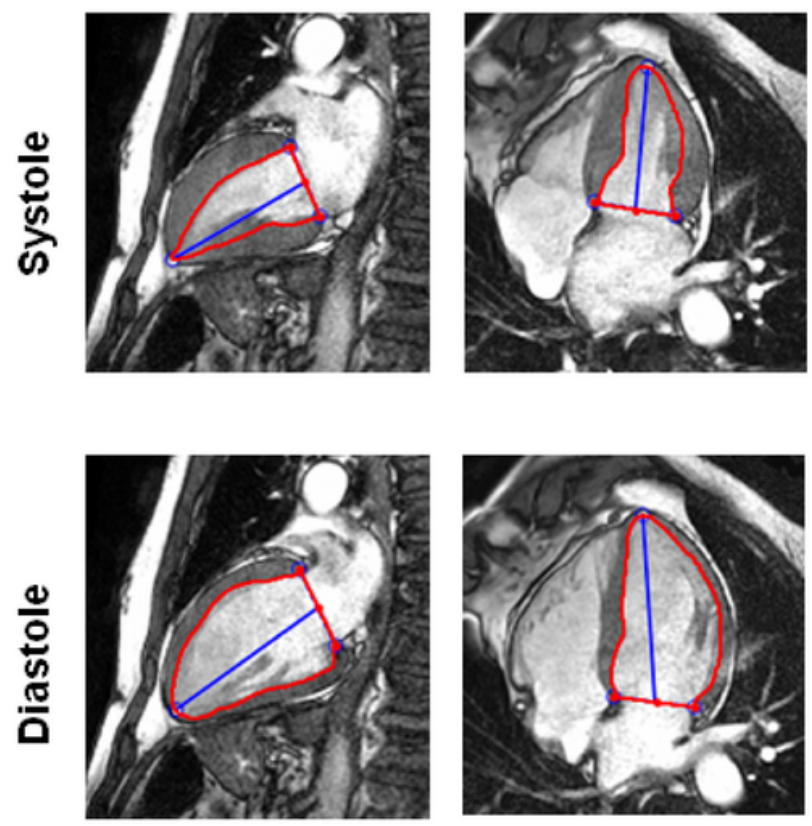

2 chamber-view

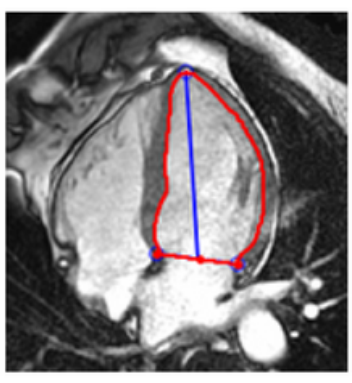

4 chamber-view 
Figure 1

Analysis of let ventricular systolic function in vertical long-axis (2 chamber) view and in horizontal longaxis ( 4 chamber) view using the biplane Simpson's method.
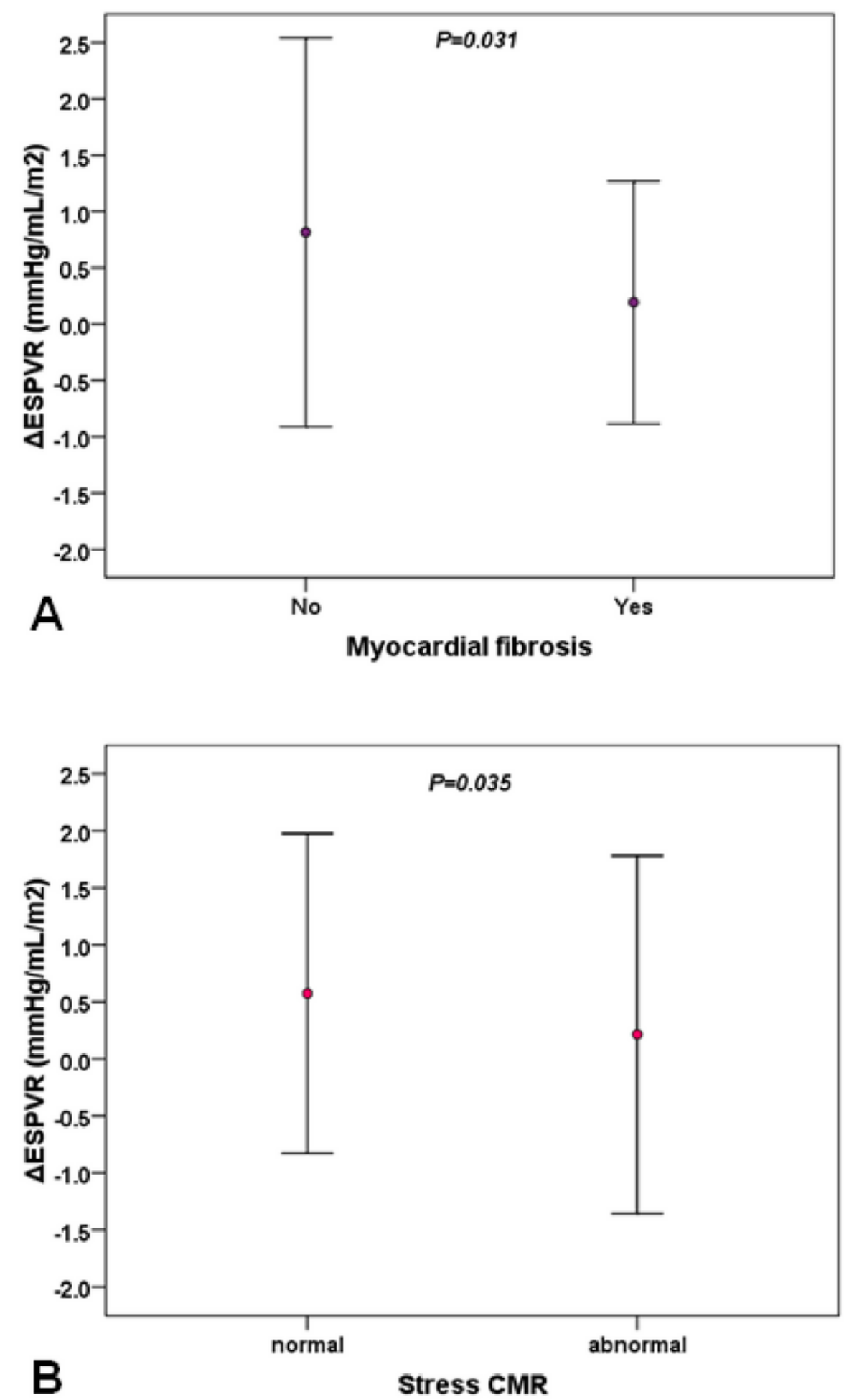

Figure 2 
Association between $\triangle E S P V R$ and CMR findings. A) $\triangle E S P V R$ in patients without and with myocardial fibrosis. B) $\triangle E S P V R$ in patients with normal and abnormal stress-CMR exam. The point indicates the mean value while the bars represent the standard deviation.
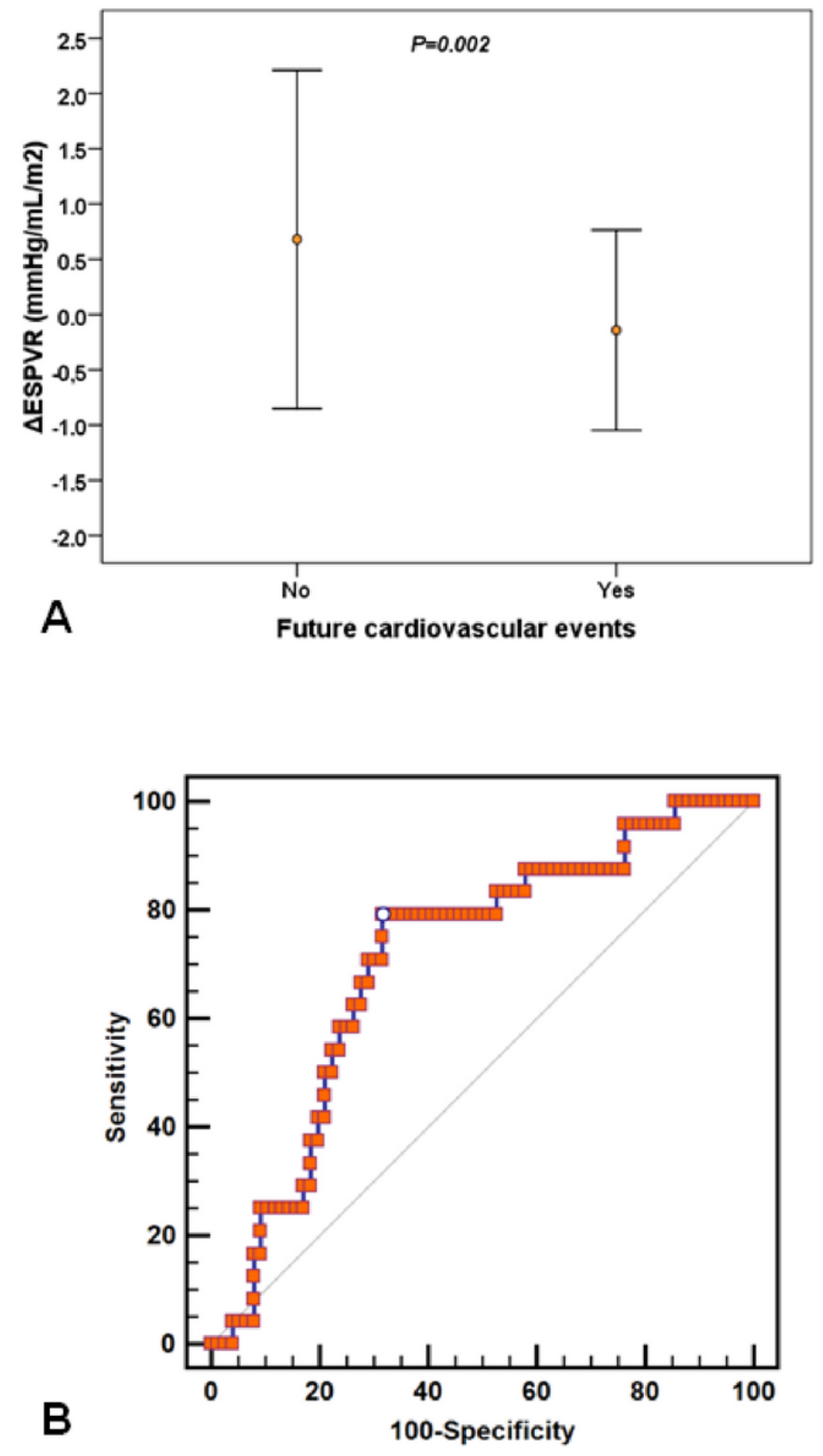

Figure 3

Association between $\triangle E S P V R$ and cardiac events. A) $\triangle E S P V R$ in patients who developed cardiac events and event-free. B) ROC curve analysis of $\triangle E S P V R$ to predict cardiovascular events. 